\title{
An Efficient Distribution Load Flow Method for Radial Distribution Systems with Load Models
}

\author{
P. Dinakara Prasad Reddy ${ }^{1}$, V. C Veera Reddy ${ }^{2}$ and T. Gowri Manohar ${ }^{3}$ \\ ${ }^{1,3}$ Department of EEE, $S$ V University, Tirupati \\ ${ }^{2}$ AITS, Tirupati \\ pdinakarprasad@gmail.com
}

\begin{abstract}
In this paper a novel efficient approach is modelled for load flow problem in distribution systems based on the distinctive topological characteristics of radial distribution networks and have been fully studied to make the direct solution possible. Due to the direct solution of the proposed method, the usage of time-consuming decomposition or bus admittance matrix in the traditional load flow methods are no longer necessary. The Branch Path Distribution Load Flow (BPDLF) algorithm needs less memory for any size of the distribution network because it uses only branch path matrix in its algorithm. Due to this it has faster convergence with less iterations. The effectiveness of the proposed method is validated on various standard IEEE test systems for different load models and compared with existing algorithms. The future load growth on various IEEE systems are also studied. Test results reveal that the proposed method is better when compared with existing algorithms.
\end{abstract}

Keywords: Load flow, Radial distribution system, primitive impedance, Branch path matrix, Load modelling

\section{Introduction}

Load flow studies are performed in distribution systems to obtain the voltage, real and reactive power flows through the distribution lines. Many applications like reactive power control, reconfiguration, loss estimation etc., require this data for analyzing various conditions in the power system. The load flow problem was solved by many methods [1-39] by exploiting the radial structure of the distribution systems available in the literature. The efficiency of the solution methods plays a vital role in all the applications which require the load flows.

The invention of digital computers made the load flow solution easy with the development of conventional methods like Gauss Seidal method, Newton Raphson method, and Decoupled and Fast Decoupled methods. However, reasons like high $\mathrm{R} / \mathrm{X}$ ratio and radial structure of distribution systems make the conventional methods unsuitable for load flow solution in distribution systems and very often the solution diverges as these are designed for mesh structures. The ac power flow problem can be solved efficiently by Newton's method. Only five iterations, each equivalent to about seven of the widely used Gauss-Seidel method, are required for an exact solution [1]. A computerized method of calculating unbalanced load flow [2] or fault currents on multi-grounded radial distribution circuits. The basic concept employed is that the electrical characteristics of any portion of an unbalanced 3phase circuit can be represented by a 6-element wye-delta network. The proposed algorithm [3] is attractive for accurate or approximate off-and on-line routine and contingency calculations for networks of any size, and can be implemented

Received (January 28, 2018), Review Result (February 20, 2018), Accepted (February 26, 2018) 
efficiently on computers with restrictive core-store capacities. A survey is presented [4] on the currently available numerical techniques for power-system load-flow calculations using the digital computer. Attention is given to the problems and techniques of adjustments in load-flow solutions, and the suitability of various methods for modern applications such as security monitoring and optimal load flow problems. The proposed method in [5] is very simple, has no mathematical approximations, and requires almost no additional storage and computation time incorporated into the normal Newton-Raphson program. K.M Brown's method [6] is used also to solve load-flow problems. The method is particularly effective for solving ill-conditioned nonlinear algebraic equations. The method proposed in [7] is efficient method for calculating the load flow solution of weakly meshed transmission and distribution systems. Its essential advantages over a previous approach are the following :(a) It uses active and reactive powers as flow variables rather than complex currents. (b) It uses an efficient tree-labeling technique which also contributes to the computational efficiency of the procedure. Proposed methods in [8-9] involves only the evaluation of a simple algebraic expression of voltage magnitude and no trigonometric functions as opposed to the standard load flow case. The classical constant-power load model is usually used to solve the load flow problem [10] of a transmission or distribution system. However, the actual load of a system is not independent of voltage magnitude. Incorporation of voltage dependent load models in the load flow algorithm is essential to get better and accurate results.

The proposed method [11] can be applied for both radial and mesh networks and a mesh network is converted to a radial network by breaking the loops through adding some dummy buses. Unlike other methods, the shunt admittances are considered in the proposed load flow algorithm and effect of admittance is also incorporated in the calculation of power injections at the LBPs. Two novel methods -sequence decoupling-compensation Newton-Raphson(SDCNR) and sequence decoupling-compensation fast-decoupled(SDCFD) methods-used for three-phase load flow studies are proposed in [12], which can be used to analyze both normal and abnormal three-phase power system steady state operation. A new algorithm [13] that is used for the solution of three-phase (or unsymmetrical) power flow analysis of both transmission and distribution systems under unsymmetrical operating conditions and power quality problems, is presented. A simple and efficient method [14] for solving radial distribution networks and involves only the evaluation of a simple algebraic expression of receiving end voltages and it is very efficient computational method. The method proposed in [15] in distribution system is first converted to an equivalent source network with radial configuration so that the conventional branch equations can be used to solve load flow problem [15]. An efficient methods for radial distribution network have been proposed [16-20]. The efficiency makes it suitable for distribution applications and fast three-phase load flow analysis. It will increase the convergence speed and bus voltages are considered as state variables. The proposed load flow algorithm[19] requires formation of bus-injection to branch current (BIBC) matrix with 1's \& 0 's as elements and branch-current to bus voltage(BCBV) matrix with primitive impedances as elements \& distribution load flow (DLF) matrix. DLF matrix is obtained as product of (BCBV) and (BIBC) matrices. These three matrices require large memory space

Owing to the radial nature and high $\mathrm{R} / \mathrm{X}$ ratio, radial distribution systems (RDS) employ a special recursive technique for distribution load flow (DLF) [21-22]. The DLF plays a critical role in automation algorithms of RDS whose scope encompasses fault isolation, network reconfiguration and service restoration. An improved backward/ forward sweep algorithm [23] for three-phase load-flow analysis of radial distribution systems. In the backward sweep, Kirchhoff's Current 
Law and Kirchhoff's Voltage Law are used to calculate the upstream bus voltage of each line or a transformer branch. Network topology [24-25] is exploited to build two matrices. One is to the sum of all active and reactive powers connected to nodes beyond a particular node. Other one is the power loss in all the lines connected beyond the node under consideration. In this method, simple algebraic expression of voltage magnitude is used. This method is very efficient and requires very less computer memory. An improved method have been proposed [26] based on electric circuit laws, this method is iterative and allows the evaluation of both, voltage (rms) values and phase angles. A novel matrix transformation technique [27-28], which directly solves the determination of branch flows in radial distribution network, consequently it makes forward backward sweep based load flow method, more effective and fast. Mekhamer et al. [29] described a method for radial distribution feeder load flow solution which is accurate and relatively fast and can be implemented for different systems. Afsari et al. [30] developed an algorithm called backward sweep algorithm for finding the load flow solution by using two methods to estimate the terminal voltages at the nodes at the start and the advantages and limitations of both the methods have been discussed.

Ranjan and Das [31] proposed a simple and efficient algorithm for solving the load flow problem in radial distribution networks by developing and solving the simple algebraic expressions involving magnitudes of the voltage with difference of real and reactive power as convergence criteria. Ghosh [32] described a simple method for solving the load flow problem for different load models in radial distribution systems which has advantages of handling the arbitrary node numbering scheme and reduced data preparation by exploiting structure. AlHajri and El-Hawry [33] developed and demonstrated a fast and flexible radial power flow technique with reduced memory and execution time based on one single building block matrix known as radial configuration matrix that uses forward or backward iterations for solving the balanced and unbalanced three phase networks by exploiting the structure. Semi definite programming is one of the most promising modeling techniques for this propose [34]. Other analytical approaches were presented in [35] and [36].

In this paper, the main objective function is to form the BPDLF matrix without the use of BCBV and BIBC matrices. This can be achieved by using branch path matrix $(\mathrm{K})$. The proposed algorithm is tested on various IEEE systems for different load models.

\section{Building of Branch Path Matrix in Proposed Load Flow Algorithm}

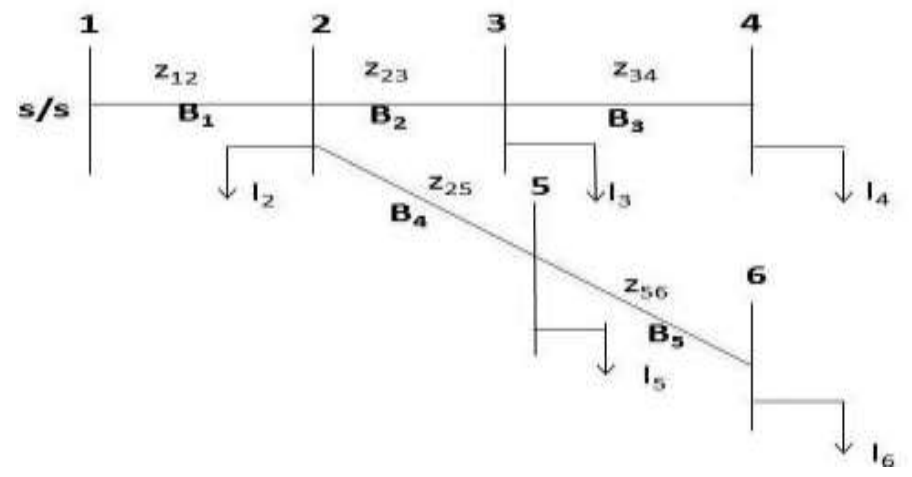

Figure 1. Simple 6 bus Radial System 
The DLF impedance matrix can be obtained by multiplication of BIBC and BIBV matrices is as shown in Equation 1. Consider a simple radial distribution network as shown in the Figure 1 for formation of proposed load flow algorithm.

$$
[\Delta v]=[D L F][I]
$$

Where, $[D L F]$ represents distribution load flow matrix given as

$$
\left[\begin{array}{ccccc}
z_{12} & z_{12} & z_{12} & z_{12} & z_{12} \\
z_{12} & z_{12}+z_{23} & z_{12}+z_{23} & z_{12} & z_{12} \\
z_{12} & z_{12}+z_{23} & z_{12}+z_{23}+z_{34} & z_{12} & z_{12} \\
z_{12} & z_{12} & z_{12} & z_{12}+z_{25} & z_{12}+z_{25} \\
z_{12} & z_{12} & z_{12} & z_{12}+z_{25} & z_{12}+z_{25}+z_{56}
\end{array}\right]
$$

From the above DLF matrix, the following useful observations are used in developing the proposed topological and primitive based distribution load flow method

1) All elements of DLF matrix of $(n-1) x(n-1)$ size are complex non-zero and symmetric.

2) Diagonal elements are given by the sum of the primitive impedances of all those lines in the path connecting the substation bus and any selected bus.

3) Each bus-p of the network can have one unique path from substation bus.

4) Off-diagonal p-q elements are given by the sum of the primitive impedances of those lines which appear common to the paths of $p$ and $q$ buses from substation bus.

These observations are effectively used in proposing the algorithm with the help of branch path $(\mathrm{k})$ matrix that exploits the topological structure of the network

\section{Proposed Solution Technique}

The proposed method directly determines the Radial distribution load flow solution by simply using primitive impendence of lines and Branch path $(\mathrm{K})$ matrix. There by need of formation of BIBC and BCBV matrix can be avoided. This new algorithm determines the elements of the DLF matrix by comparing rows and columns of the branch path $(\mathrm{K})$ matrix .Thus [ $\Delta v$ ] elements of the Equation [1] can be determined easily. The proposed approach offers very significant saving in computational burden as it avoids the formation of BIBC and BCBV matrix with exact results at the end.it also requires less iterations for convergence criteria when compared with other solution techniques.

\subsection{Formation of DLF Matrix Elements using Branch path (K) matrix}

A Typical 6-bus radial distribution network as shown in Figure1 is considered in order to explain the DLF matrix elements formation by using Branch path $(\mathrm{K})$ matrix. The $\mathrm{K}$-matrix can be formed from reduced incidence matrix (A). $\mathrm{K}=$ transpose(inverse $(\mathrm{A})$ ). The $\mathrm{K}$-matrix for stated 6-Bus radial distribution network is given by

$$
\left[\begin{array}{lllll}
1 & 0 & 0 & 0 & 0 \\
1 & 1 & 0 & 0 & 0 \\
1 & 1 & 1 & 0 & 0 \\
1 & 0 & 0 & 1 & 0 \\
1 & 0 & 0 & 1 & 1
\end{array}\right]
$$


The $\mathrm{k}$ matrix is a combination of 0 's and 1's. The 1's representation in a row of a Branch path matrix gives information about connecting path between node-1 and any selected node. Thus, diagonal elements of DLF matrix can be formed.

For example, the fourth row in above k matrix has 1's in first column and fourth column therefore diagonal element in fourth row is summation of $z_{12}$ and $z_{25}$ i.e., $Z_{44}=z_{12}+z_{25}$. Similarly, when rows of the $\mathrm{K}$ matrix are compared, if there exists a common 1's in respective columns then summation of those primitive impedance will gives respective off diagonal elements of the DLF matrix. For example, $Z_{23}$ of DLF matrix can be formed by comparing second row and third row which gives summation of $z_{12}$ and $z_{23}$.i.e., $Z_{23}=z_{12}+z_{23}$.

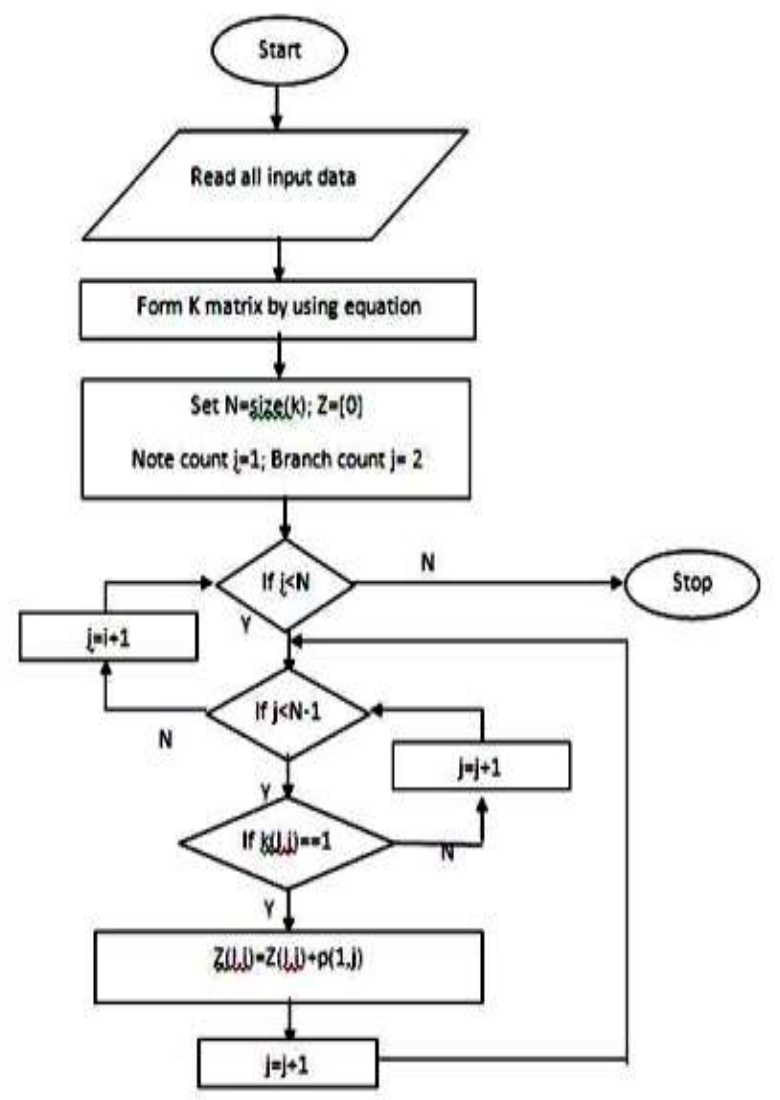

Figure 2. Flow Chart for Formation of DLF Matrix

\section{Proposed Distribution Load Flow Algorithm}

1. Read the distribution system data and Initialize the Bus Voltages to $1+j 0$ p.u.

2. Form the Branch path matrix using Equation (1).

3. Add all the primitive impedances of all those lines by direct comparison of 1 's in $\mathrm{K}$ matrix as shown in Figure 2.

4. Calculate the Power Injections and Current Injections $I[i]$ at all the buses

5. Assign $I[i]^{\text {old }}=I[i]$ for all the buses.

6. As discussed in Figure 2 calculate the $\Delta v$ elements of the Equation [ $\Delta v$ ]= $[D L F][I]$

7. Choose proper load model. Update the bus voltages at all the buses.

8. Calculate the current Injections $I[i]$ with the updated bus voltages. 
9. If $\max \left(\left|I[i]^{k+1}-I[i]^{k}\right|\right)>$ tolerance, then advance the iteration count and go to step 7.

10. Print the converged load flow solution for different load models and Stop.

\section{Load Modelling}

Distribution load flow studies have been intensely impacted by Load modelling. Load flow solutions and convergence ability are greatly affected by load characteristics.

Load models are usually classified into two main categories i.e., static and dynamic load models.

1 Static load model: Static load model expresses the active and reactive power at any instant of time as functions of the bus voltage magnitude and frequency at the same instant. Static load models are used for essentially static load components such as resistive and lighting loads, and as an approximation for dynamic load components, such as, motor driven loads.

2 Dynamic load model: Dynamic load model expresses the active and reactive powers at any instant of time as functions of the bus voltage magnitude and frequency at past instants of time and, usually, including the present instant. These types of models are represented by using differential equations.

As load flow analysis is mainly performed for static states of power systems only static load model is considered. Load that can be modelled either as constant power, constant current, constant impedance and composite load or as an exponential load is considered here. The general expression of load is shown below.

$$
\begin{aligned}
& P L=P L_{0}\left(\frac{V}{V_{0}}\right)^{n p} \\
& Q L=Q L_{0}\left(\frac{V}{V_{0}}\right)^{n q}
\end{aligned}
$$

Where $n p$ and $n q$ stand for load exponents, $\mathrm{V}$ and $V_{0}$ stand for load bus voltage and load nominal voltage, respectively. $P L_{0}$ and $Q L_{0}$ stand for the values of the active and reactive powers at the nominal voltages. The load can be represented as constant power, constant current, or constant impedance models by setting the exponents to 0,1 , or 2 respectively. The aggregate effect of different types of load components can be represented by using other exponents. Common values for the exponents for different static loads are given in following Table 1 .

Polynomial load model: It is a static load model where the voltage magnitude is related to the power as a polynomial equation, usually in the following form

$$
\begin{aligned}
& P L=P L_{0}\left[a_{1}+a_{2}\left(\frac{V}{V_{0}}\right)^{1}+a_{3}\left(\frac{V}{V_{0}}\right)^{2}\right] \\
& Q L=Q L_{0}\left[b_{1}+b_{2}\left(\frac{V}{V_{0}}\right)^{1}+b_{3}\left(\frac{V}{V_{0}}\right)^{2}\right]
\end{aligned}
$$

The coefficients $a_{1}$ to $a_{3}$ and $b_{1}$ to $b_{3}$ are the parameters of this model. This model is sometimes referred to as the "ZIP" model as it consists of the sum of constant impedance (Z), constant current (I), and constant power (P) terms. 
Table 1. Common Values for the Exponents for Different Static Loads

\begin{tabular}{|l|l|l|l|}
\hline S.No & \multicolumn{1}{|c|}{ Load components } & \multicolumn{1}{c|}{$\boldsymbol{n p}$} & \multicolumn{1}{c|}{$\boldsymbol{q q}$} \\
\hline 1 & Constant Power & 0.00 & 0.00 \\
\hline 2 & Constant current & 1.00 & 1.00 \\
\hline 3 & Constant impedance & 2.00 & 2.00 \\
\hline 4 & Incandescent light & 1.55 & 0.00 \\
\hline 5 & Fluorescent light & 0.96 & 7.38 \\
\hline 6 & Air conditioner & 0.20 & 2.30 \\
\hline 7 & Dryer & 2.04 & 3.27 \\
\hline 8 & Freezer & 0.77 & 2.50 \\
\hline 9 & Heater & 2.00 & 0.00 \\
\hline 10 & Pumps,fans etc & 0.08 & 1.60 \\
\hline 11 & Computer,T.V. etc & 2.00 & 5.20 \\
\hline & & &
\end{tabular}

4.1. The Effect of Change of Operating Voltage on Different Types of Load Models

The effect of change of operating voltage with respect to load current for constant power, constant current, constant impedance types of loads is shown in Figure 3.

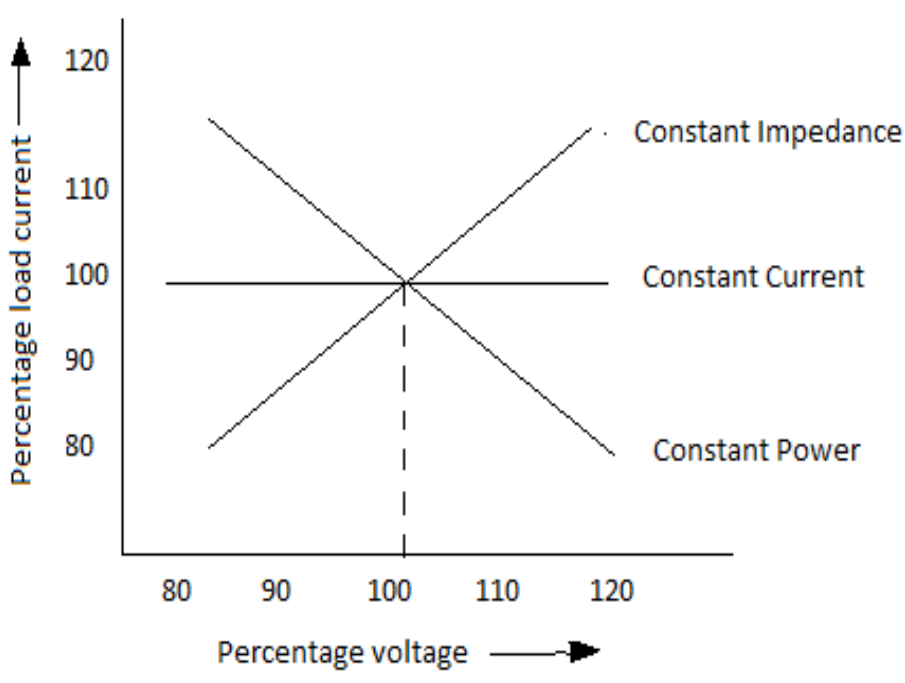

Figure 3. Behaviour of Constant Current, Constant Power and Constant Impedance Loads with Respect to Current Loading as a Function of Voltage Variations

The effect of change of operating voltage with respect to load MVA on constant power, constant current, constant impedance types of loads is shown in Figure 4. 


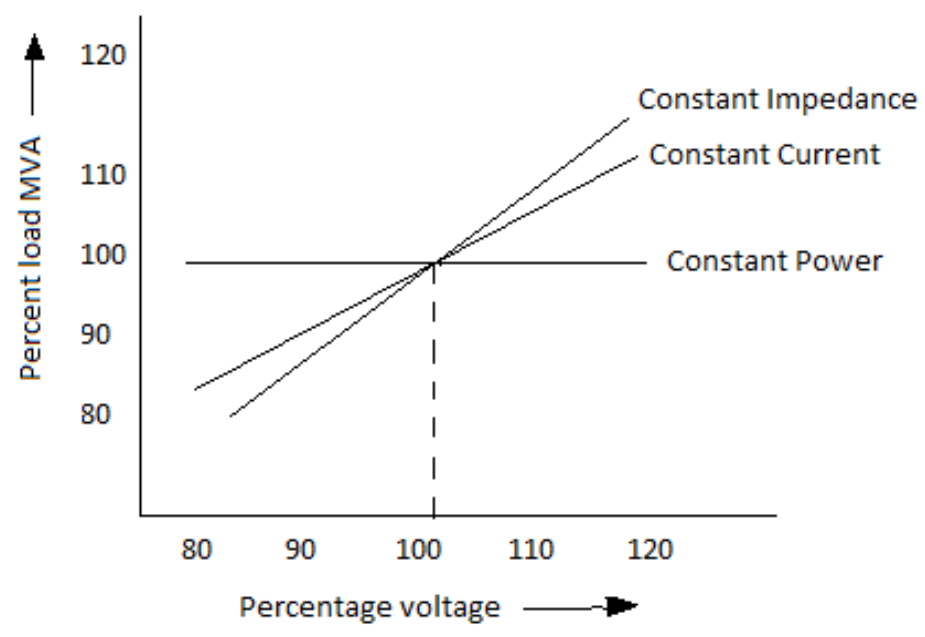

Figure 4. Behaviour of Constant Current, Constant Power and Constant Impedance Loads with Respect to MVA Loading as a Function of Voltage Variations

\section{Load Growth}

In a geographical area, load growth is the most important factor influencing the expansion of a distribution system. Therefore, the future estimate of the system must be known to a system engineer for planning, expansion and efficient operation of the distribution systems.

By knowing the load growth rate, the real and reactive power loads at end of the nth year is given by

$$
\begin{aligned}
& P L_{n}=P L_{0}(1+g / 100)^{n} \\
& Q L_{n}=Q L_{0}(1+g / 100)^{n}
\end{aligned}
$$

Where $P L_{n}$ is the real power load at the end of the nth year. $Q L_{n}$ is the reactive power load at the end of the nth year. $P L_{0}$ is the initial real power load. $Q L_{0}$ is the initial reactive power load. $\mathrm{g}$ is the annual load growth rate. $\mathrm{n}$ is the number of years.

Here, the following load growth scenarios are considered for a period of $n=5$ years in the load flow calculations.
Case (i) No load growth
Case (ii) Slight load growth
(0\% annual load growth )
Case (iii) Average load growth
(2\% annual load growth)
Case (iv) Fast load growth
(5\% annual load growth)
(7\% annual load growth)

\section{Test Results}

In load flow studies of distribution systems, the classical constant power load model is usually used. The Branch path Distribution load flow (BPDLF) algorithm is applied on various IEEE standard systems. The BPDLF algorithm requires less number of iterations due to direct comparisons of 1's in Branch path matrix which leads to the faster convergence. The proposed algorithm converges in less iterations when compared with existing algorithms in Table 2. 
Table 2. Comparative Study of Various Algorithms

\begin{tabular}{|c|c|c|c|c|c|c|}
\hline \multirow{2}{*}{ S.NO } & \multirow{2}{*}{$\begin{array}{c}\text { Type of } \\
\text { algorithms }\end{array}$} & $\begin{array}{c}\text { IEEE 15 } \\
\text { bus }\end{array}$ & $\begin{array}{c}\text { IEEE 34 } \\
\text { bus }\end{array}$ & $\begin{array}{c}\text { IEEE 69 } \\
\text { bus }\end{array}$ & $\begin{array}{c}\text { IEEE 85 } \\
\text { bus }\end{array}$ & $\begin{array}{c}\text { IEEE } \\
\text { 118 bus }\end{array}$ \\
\cline { 2 - 7 } & Iterations & Iterations & Iterations & Iterations & Iteration \\
\hline 1 & $\begin{array}{c}\text { Ghosh and Das } \\
{[17]}\end{array}$ & 7 & 7 & 8 & 10 & - \\
\hline 2 & $\begin{array}{c}\text { Renato method } \\
{[11]}\end{array}$ & 4 & 4 & 4 & - & - \\
\hline 3 & Kersting [6] & 4 & 4 & 4 & - & - \\
\hline 4 & AbulWafa [39] & 4 & 4 & 4 & - & - \\
\hline 5 & Proposed method & 3 & 3 & 4 & 4 & 4 \\
\hline
\end{tabular}

\subsection{Load Modelling Results}

The Brach Path Distribution Load Llow(BPDLF) method is used for performing Load flow analysis for different static loads shown in Table 1, such as Constant power load, Constant current load, Constant impedance load, Incandescent light load, Fluorescent light load, Air conditioner load, Dryer load, Freezer load, Heater load, Pumps \& Fans load and Computer \& T.V. load.

In the load flow analysis, the real and reactive power loads are modified using the Equations (3) and (4), after each update of bus voltages.

7.1.1. Case 1: Each static load is considered separately to perform load flow analysis. Load flow results of 15-bus system for different static loads are shown in Table 3 and Load flow results of different test systems for different static loads are shown in Table 4 below.

7.1.2. Case 2: Composite load of $(40 \%$ constant power load $+30 \%$ constant impedance load $+30 \%$ constant current load) is considered for performing load flow analysis. Load flow results of different test systems for the composite load are shown in Table 5.

Table 5. Load Flow Results of Different Test Systems for the Composite Load

\begin{tabular}{|l|c|c|c|c|}
\hline S.No & System & TPL $(\mathbf{k W})$ & TQL(kVAr) & Iterations \\
\hline 1 & 15 bus & 56.74 & 52.60 & 2 \\
\hline 2 & 34 bus & 204.36 & 60.10 & 2 \\
\hline 3 & 69 bus & 195.16 & 89.40 & 3 \\
\hline 4 & 85 bus & 260.26 & 163.76 & 2 \\
\hline
\end{tabular}

7.1.3. Case 3: Industrial load of (30\% incandescent light $+49 \%$ fluorescent light + $21 \%$ air conditioner load) is considered to perform load flow analysis for different test systems. Load flow results of different test systems for the industrial load are shown in Table 6. 
Table 6. Load Flow Results of Different Test Systems for the Industrial Load

\begin{tabular}{|c|c|c|c|c|}
\hline S No & System & TPL(kW) & TQL(kVAr) & Iterations \\
\hline 1 & 15 bus & 50.17 & 46.52 & 4 \\
\hline 2 & 34 bus & 189.69 & 55.0935 & 4 \\
\hline 3 & 69 bus & 170.23 & 78.04 & 5 \\
\hline 4 & 85 bus & 206.23 & 129.95 & 6 \\
\hline
\end{tabular}

Table 3. Load Flow Results of 15-Bus System for Different Static Load

\begin{tabular}{|c|c|c|c|c|c|c|c|c|c|c|c|c|c|c|c|c|c|c|c|}
\hline 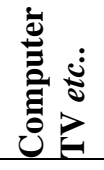 & & $\begin{array}{l}8 \\
8 \\
8 \\
\end{array}$ & $\begin{array}{l}\hat{n} \\
\hat{\sigma} \\
\hat{0}\end{array}$ & $\begin{array}{l}\text { స్ర } \\
\text { ఏ్ }\end{array}$ & $\begin{array}{l}0 \\
\infty \\
\\
\vdots \\
0\end{array}$ & $\begin{array}{l}\hat{n} \\
\hat{\sigma}\end{array}$ & 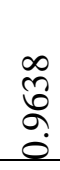 & $\begin{array}{l}\frac{a}{0} \\
\vdots \\
0\end{array}$ & 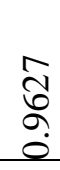 & $\begin{array}{c}\hat{N} \\
\hat{\sigma}\end{array}$ & $\frac{n}{\hat{a}}$ & $\begin{array}{l}\bar{n} \\
\hat{\sigma} \\
0\end{array}$ & $\begin{array}{l}0 \\
\tilde{n} \\
\hat{\sigma} \\
\vdots \\
0\end{array}$ & $\begin{array}{l}\hat{n} \\
\hat{\sigma} \\
\vdots \\
0\end{array}$ & 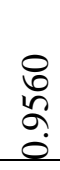 & $\begin{array}{l}\hat{n} \\
\hat{\sigma} \\
\hat{\sigma}\end{array}$ & $\underset{⿱ 亠}{\stackrel{+}{g}}$ & $\begin{array}{l}\stackrel{P}{+} \\
\text { i }\end{array}$ & 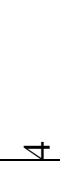 \\
\hline 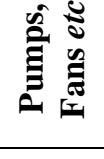 & & 8 & 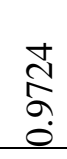 & 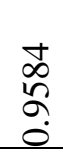 & 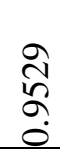 & $\begin{array}{l}\frac{a}{n} \\
\grave{0}\end{array}$ & $\begin{array}{l}\hat{\sigma} \\
\hat{\sigma} \\
\hat{0}\end{array}$ & $\begin{array}{l}\frac{0}{n} \\
\hat{n} \\
\vdots\end{array}$ & $\begin{array}{l}n \\
\infty \\
\swarrow \\
\vdots \\
0\end{array}$ & $\begin{array}{l}\bar{\sigma} \\
\text { aे } \\
\text { o. }\end{array}$ & $\begin{array}{l}\infty \\
\infty \\
0 \\
0 \\
0\end{array}$ & $\begin{array}{l}\frac{\sigma}{n} \\
\hat{0}\end{array}$ & \begin{tabular}{l}
$\stackrel{0}{0}$ \\
\multirow{+}{+}{} \\
0
\end{tabular} & $\begin{array}{l}\hat{0} \\
\text { d. } \\
0\end{array}$ & $\begin{array}{l}\hat{\circ} \\
\hat{n} \\
\hat{0}\end{array}$ & $\begin{array}{l}n \\
\hat{n} \\
\hat{n} \\
0\end{array}$ & $\begin{array}{l}\infty \\
\text { ô } \\
n\end{array}$ & $\begin{array}{l}\infty \\
\infty \\
i \\
n\end{array}$ & $m$ \\
\hline 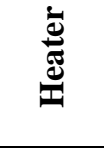 & & $\begin{array}{l}8 \\
\delta \\
8 \\
\end{array}$ & 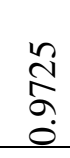 & $\begin{array}{l}\hat{n} \\
\infty \\
\hat{\sigma} \\
\hat{0}\end{array}$ & $\begin{array}{l}0 \\
\tilde{n} \\
\hat{\sigma} \\
0\end{array}$ & $\begin{array}{l}\bar{N} \\
\grave{\sigma} \\
\vdots\end{array}$ & $\begin{array}{l}8 \\
8 \\
\circ \\
0\end{array}$ & $\begin{array}{l}\frac{a}{\hat{n}} \\
\hat{\sigma} \\
0\end{array}$ & $\begin{array}{l}\infty \\
\infty \\
\swarrow \\
\vdots \\
0\end{array}$ & $\begin{array}{l}\hat{\sigma} \\
\hat{\sigma} \\
\hat{0}\end{array}$ & $\begin{array}{l}1 \\
0 \\
0 \\
0 \\
0 \\
0\end{array}$ & 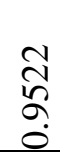 & 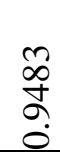 & 疍 & $\begin{array}{l}\infty \\
\stackrel{0}{\circ} \\
\stackrel{n}{0} \\
0\end{array}$ & $\begin{array}{l}\hat{\circ} \\
\hat{n} \\
\hat{0}\end{array}$ & $\begin{array}{l}\hat{a} \\
\text { n̊ }\end{array}$ & $\begin{array}{l}\text { ô } \\
\text { in } \\
\text { in }\end{array}$ & $m$ \\
\hline 遏 & $\doteq$ & $\underset{8}{8}$ & $\stackrel{m}{\hat{\sigma}}$ & $\begin{array}{l}\stackrel{2}{\sigma} \\
\hat{\sigma} \\
\hat{\sigma}\end{array}$ & $\begin{array}{l}\frac{n}{2} \\
\hat{n} \\
0\end{array}$ & $\begin{array}{l}0 \\
\tilde{n} \\
\hat{\sigma} \\
0\end{array}$ & $\begin{array}{l}\overline{7} \\
\vdots \\
0\end{array}$ & $\begin{array}{l}8 \\
2 \\
2 \\
0\end{array}$ & $\begin{array}{l}\hat{\alpha} \\
\hat{n} \\
\hat{\sigma}\end{array}$ & $\begin{array}{l}\frac{1}{2} \\
\hat{\sigma} \\
0\end{array}$ & 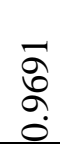 & $\begin{array}{l}0 \\
\tilde{n} \\
\hat{\sigma} \\
0\end{array}$ & $\begin{array}{l}\stackrel{\infty}{\stackrel{+}{+}} \\
\stackrel{\sigma}{0}\end{array}$ & 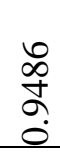 & $\begin{array}{l}\stackrel{+}{\sim} \\
\hat{\sigma} \\
0\end{array}$ & $\begin{array}{l}\hat{N} \\
\hat{\sigma} \\
0\end{array}$ & $=$ & $\begin{array}{r}\hat{n} \\
\stackrel{a}{\sigma}\end{array}$ & $m$ \\
\hline$\stackrel{\grave{D}}{\grave{D}}$ & 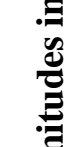 & 8 & $\frac{⿱}{\Delta}$ & $\begin{array}{l}n \\
\vdots \\
0 \\
0\end{array}$ & $\begin{array}{l}\tilde{b} \\
\tilde{\sigma} \\
\vdots \\
0\end{array}$ & $\begin{array}{l}\stackrel{\circ}{n} \\
\tilde{\sigma} \\
\vdots\end{array}$ & $\begin{array}{l}\hat{\sigma} \\
\text { o̊ } \\
0\end{array}$ & $\begin{array}{l}5 \\
\delta \\
0 \\
0\end{array}$ & $\begin{array}{l}n \\
\frac{n}{2} \\
0 \\
0\end{array}$ & $\frac{m}{\hat{\sigma}}$ & 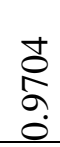 & $\begin{array}{l}\stackrel{0}{n} \\
\tilde{n} \\
\vdots \\
0\end{array}$ & $\begin{array}{l}\stackrel{N}{2} \\
\hat{\sigma} \\
0\end{array}$ & $\begin{array}{l}\hat{O} \\
\hat{n} \\
\hat{0}\end{array}$ & \begin{tabular}{l}
\multirow{2}{2}{} \\
$\stackrel{2}{0}$ \\
0
\end{tabular} & $\begin{array}{l}\stackrel{3}{+} \\
\grave{0} \\
0\end{array}$ & $\begin{array}{l}\stackrel{2}{1} \\
\infty \\
+\infty\end{array}$ & $\begin{array}{l}\text { ị } \\
i v\end{array}$ & $\theta$ \\
\hline 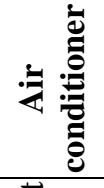 & 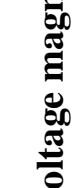 & $\begin{array}{l}8 \\
8 \\
8\end{array}$ & $\frac{\hat{d}}{\hat{\sigma}}$ & $\begin{array}{l}\bar{\sigma} \\
\hat{\sigma} \\
\hat{0}\end{array}$ & $\begin{array}{l}\hat{n} \\
\hat{n} \\
\hat{0}\end{array}$ & 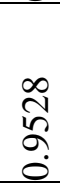 & $\begin{array}{l}\text { t } \\
8 \\
0 \\
0\end{array}$ & $\begin{array}{l}\tilde{\infty} \\
\tilde{n} \\
\hat{0}\end{array}$ & $\begin{array}{l}\tilde{\sigma} \\
\tilde{\sigma} \\
\tilde{0}\end{array}$ & $\begin{array}{l}\hat{a} \\
\hat{0} \\
\hat{0}\end{array}$ & $\begin{array}{l}0 \\
\infty \\
0 \\
0 \\
0\end{array}$ & $\begin{array}{l}\stackrel{\infty}{N} \\
\stackrel{n}{0} \\
0\end{array}$ & $\begin{array}{l}2 \\
\text { +े } \\
\vdots \\
0\end{array}$ & 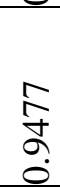 & $\begin{array}{l}0 \\
\hat{n} \\
\hat{\sigma}\end{array}$ & $\frac{ \pm}{\tilde{n}}$ & $\begin{array}{l}0 \\
\dot{n} \\
\ddot{n}\end{array}$ & $\frac{\sigma}{n}$ & $m$ \\
\hline 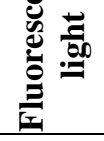 & & 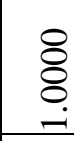 & $\frac{t}{2}$ & $\begin{array}{l}0 \\
\text { గి } \\
\text { مे } \\
0\end{array}$ & $\begin{array}{l}\hat{\infty} \\
\stackrel{2}{\alpha} \\
\hat{0}\end{array}$ & $\begin{array}{l}n \\
\hat{n} \\
\hat{0}\end{array}$ & $\begin{array}{l}\hat{\text { हे }} \\
\text { ڤे }\end{array}$ & $\begin{array}{l}\text { స్ } \\
\text { مे } \\
0\end{array}$ & $\begin{array}{l}0 \\
\text { గి } \\
\text { مे } \\
0\end{array}$ & 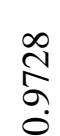 & $\frac{ \pm}{\hat{\sigma}}$ & $\frac{N}{\hat{n}}$ & $\begin{array}{l}\hat{n} \\
\hat{n} \\
0\end{array}$ & 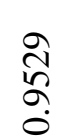 & 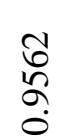 & $\begin{array}{l}8 \\
\stackrel{0}{2} \\
\hat{\sigma} \\
0\end{array}$ & $\vec{r}$ & $\begin{array}{l}\infty \\
\stackrel{\infty}{\sim} \\
\sim\end{array}$ & in \\
\hline 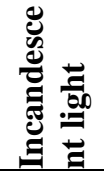 & & 8 & 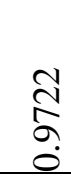 & $\begin{array}{l}\infty \\
\stackrel{\infty}{\alpha} \\
\vdots \\
0\end{array}$ & $\begin{array}{l}\stackrel{0}{N} \\
\hat{n} \\
\hat{0}\end{array}$ & $\begin{array}{l}0 \\
\hat{n} \\
\hat{\sigma}\end{array}$ & $\begin{array}{l}\stackrel{2}{\circ} \\
\hat{n} \\
\hat{0}\end{array}$ & $\begin{array}{l}n \\
\hat{n} \\
\hat{0}\end{array}$ & $\begin{array}{l}+ \\
\infty \\
\swarrow \\
\vdots \\
0\end{array}$ & 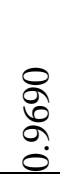 & $\begin{array}{l}0 \\
8 \\
0 \\
\vdots \\
0\end{array}$ & $\frac{\tilde{n}}{\hat{\sigma}}$ & \begin{tabular}{l}
$\infty$ \\
\multirow{\sigma}{*}{} \\
$\vdots$ \\
0
\end{tabular} & $\begin{array}{l}n \\
6 \\
\vdots \\
0 \\
0\end{array}$ & $\begin{array}{l}\dot{0} \\
\stackrel{n}{\sigma} \\
0\end{array}$ & $\begin{array}{l}\hat{\delta} \\
\stackrel{n}{0} \\
0\end{array}$ & $\underset{\infty}{\infty}$ & $\begin{array}{l}\hat{\sigma} \\
\dot{n}\end{array}$ & $m$ \\
\hline 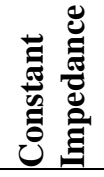 & & 8. & $\stackrel{\hat{n}}{\hat{\sigma}}$ & $\begin{array}{l}n \\
\hat{\delta} \\
\vdots \\
0\end{array}$ & $\begin{array}{l}n \\
\hat{n} \\
\hat{\sigma} \\
0\end{array}$ & \begin{tabular}{l}
\multirow{2}{*}{} \\
$\hat{\sigma}$ \\
0
\end{tabular} & $\begin{array}{l}5 \\
5 \\
0 \\
0\end{array}$ & $\begin{array}{l}\hat{\sigma} \\
\hat{n} \\
\hat{0}\end{array}$ & $\begin{array}{l}\circ \\
8 \\
0 \\
\vdots \\
0\end{array}$ & $\begin{array}{l}\stackrel{8}{0} \\
\vdots \\
0\end{array}$ & $\begin{array}{l}\circ \\
\text { ठ̊ } \\
\text { ఏे }\end{array}$ & $\begin{array}{l}\stackrel{8}{2} \\
\stackrel{n}{0} \\
0\end{array}$ & $\begin{array}{l}\hat{o} \\
\hat{n} \\
\hat{0}\end{array}$ & 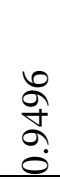 & $\begin{array}{l}\tilde{n} \\
\tilde{n} \\
\hat{0}\end{array}$ & $\begin{array}{l}\bar{n} \\
\hat{n} \\
\hat{0}\end{array}$ & $\frac{n}{n}$ & 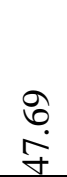 & $m$ \\
\hline 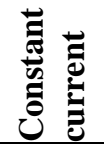 & & ஜ & $\begin{array}{l}\stackrel{o}{N} \\
\hat{\sigma} \\
0\end{array}$ & $\begin{array}{l}\hat{\infty} \\
\hat{\sigma} \\
\hat{0}\end{array}$ & $\begin{array}{l}\tilde{\sigma} \\
\hat{n} \\
\hat{0}\end{array}$ & $\begin{array}{l}\hat{N} \\
\hat{\sigma} \\
\hat{0}\end{array}$ & $\begin{array}{l}\overline{8} \\
\vdots \\
0 \\
0\end{array}$ & $\begin{array}{l}8 \\
\infty \\
\hat{\sigma} \\
\hat{0}\end{array}$ & $\begin{array}{l}2 \\
\infty \\
\hat{\sigma} \\
\vdots \\
0\end{array}$ & 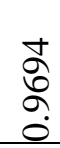 & 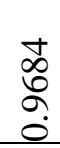 & $\begin{array}{l}\stackrel{\Delta}{\sigma} \\
\hat{\sigma}\end{array}$ & 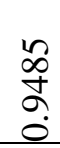 & 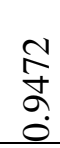 & $\begin{array}{l}\bar{n} \\
\hat{\sigma}\end{array}$ & $\begin{array}{l}\hat{\circ} \\
\hat{n} \\
\hat{o}\end{array}$ & $\begin{array}{l} \pm \\
\dot{0}\end{array}$ & $\begin{array}{l}n \\
\text { in } \\
\text { n }\end{array}$ & - \\
\hline
\end{tabular}




\begin{tabular}{|c|c|c|c|c|c|c|c|c|c|c|c|c|c|c|c|c|c|c|c|}
\hline 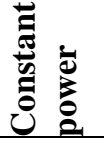 & & $\underset{8}{8}$ & $\frac{m}{\hat{\sigma}}$ & 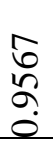 & $\begin{array}{l}\stackrel{o}{\circ} \\
\hat{n} \\
\vdots \\
0\end{array}$ & $\begin{array}{l}\text { ईे } \\
\text { gे } \\
\text { Oे }\end{array}$ & 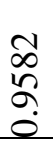 & $\begin{array}{l}\stackrel{8}{0} \\
\curvearrowleft \\
\vdots \\
0\end{array}$ & $\begin{array}{l}\stackrel{2}{n} \\
\mathfrak{n} \\
\vdots\end{array}$ & 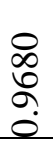 & 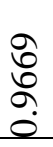 & 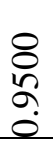 & \begin{tabular}{l}
$\infty$ \\
\multirow{2}{*}{} \\
$\vdots$ \\
$\vdots$ \\
0
\end{tabular} & 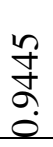 & \begin{tabular}{l}
0 \\
\multirow{2}{\infty}{} \\
$\vdots$ \\
0
\end{tabular} & 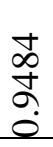 & $\frac{2}{6}$ & ì & 0 \\
\hline 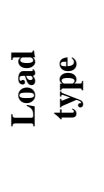 & $\begin{array}{l}0 \\
z \\
0 \\
0 \\
0\end{array}$ & - & $N$ & $m$ & $\nabla$ & in & 6 & $r$ & $\infty$ & $a$ & $\varrho$ & $=$ & $\simeq$ & $\cong$ & \pm & $\stackrel{2}{2}$ & $\underbrace{\frac{1}{2}}_{1}$ & 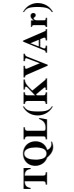 & \\
\hline
\end{tabular}

Table 4. Load Flow Results Different Bus System for Different Static

Load

\begin{tabular}{|c|c|c|c|c|c|c|c|c|c|c|c|c|c|c|c|c|}
\hline 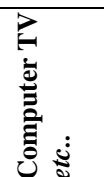 & \multirow{9}{*}{ 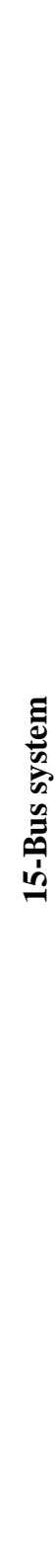 } & $\underset{⿱ 亠}{\stackrel{+}{\sigma}}$ & 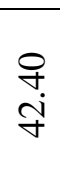 & $\nabla$ & \multirow{9}{*}{ 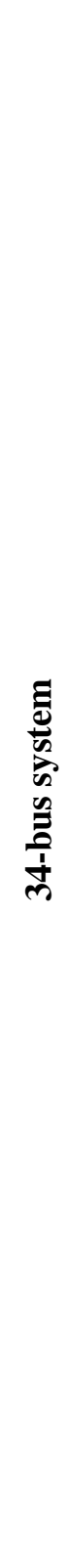 } & ?ֶ? & $\begin{array}{l}n \\
\text { ñ } \\
\text { हn }\end{array}$ & $\nabla$ & \multirow{9}{*}{ 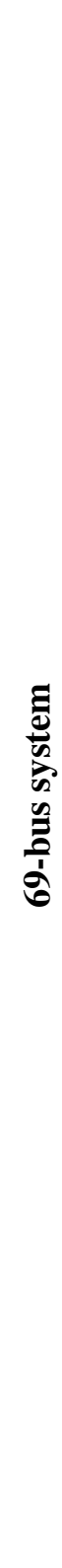 } & $\begin{array}{l}\hat{b} \\
\dot{0} \\
\pm\end{array}$ & $\begin{array}{l}n \\
\infty \\
\infty\end{array}$ & 6 & \multirow{9}{*}{ 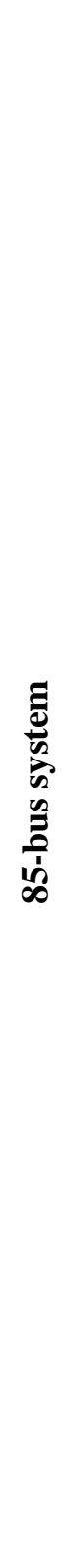 } & $\begin{array}{l}\vec{\gamma} \\
\dot{0} \\
0 \\
0\end{array}$ & $\begin{array}{l}\vec{\sim} \\
\stackrel{8}{\varrho}\end{array}$ & $n$ \\
\hline 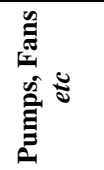 & & 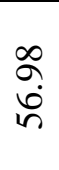 & $\begin{array}{l}\infty \\
\infty \\
i \\
i\end{array}$ & $m$ & & $\begin{array}{l}\infty \\
\infty \\
\infty \\
\stackrel{\sim}{0}\end{array}$ & $\hat{\sigma}$ & $m$ & & 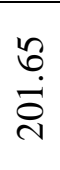 & $\begin{array}{c}\text { ה̃ } \\
\text { }\end{array}$ & $\nabla$ & & $\frac{7}{i}$ & $\begin{array}{l}0 \\
\stackrel{0}{0} \\
\underline{0}\end{array}$ & $m$ \\
\hline 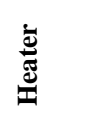 & & $\begin{array}{l}\hat{\sigma} \\
\hat{\wp}\end{array}$ & $\begin{array}{l}\text { D } \\
\text { in } \\
\text { nn }\end{array}$ & $m$ & & $\begin{array}{l}\stackrel{8}{0} \\
\stackrel{8}{8}\end{array}$ & $\begin{array}{l}\text { ô. } \\
\text { in }\end{array}$ & $m$ & & $\begin{array}{l}\stackrel{ }{2} \\
\text { ล̇ }\end{array}$ & $\begin{array}{l}\stackrel{\infty}{\sim} \\
\infty \\
\infty\end{array}$ & $\forall$ & & $\frac{\sqrt{n}}{\sqrt[n]{n}}$ & $\begin{array}{l}0 \\
\stackrel{0}{0} \\
\sigma \\
-\end{array}$ & $\nabla$ \\
\hline 离 & & $=$ & $\begin{array}{l}\stackrel{\leftrightarrow}{q} \\
\stackrel{q}{q}\end{array}$ & $m$ & & $\begin{array}{l}\text { ปุ } \\
\stackrel{2}{2}\end{array}$ & 年 & $m$ & & $\begin{array}{l}\infty \\
\stackrel{0}{0} \\
\stackrel{\infty}{0}\end{array}$ & $\begin{array}{l}\stackrel{\infty}{\sim} \\
\infty \\
\infty\end{array}$ & $\nabla$ & & $\frac{n}{\stackrel{N}{N}}$ & $\begin{array}{l}\stackrel{8}{ } \\
\dot{ \pm} \\
\underline{J}\end{array}$ & $\nabla$ \\
\hline$\stackrel{\grave{D}}{\Delta}$ & & $\begin{array}{l}\stackrel{2}{2} \\
\stackrel{\infty}{+}\end{array}$ & 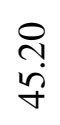 & $\nabla$ & & $\begin{array}{l}\stackrel{0}{2} \\
\infty \\
\infty\end{array}$ & $\begin{array}{l}\stackrel{ }{i} \\
\text { in }\end{array}$ & $\nabla$ & & 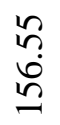 & $\begin{array}{l}\bar{\infty} \\
\stackrel{i}{ }\end{array}$ & $n$ & & $\frac{n}{n} \underset{N}{N}$ & $\begin{array}{l}\stackrel{8}{0} \\
\stackrel{0}{m} \\
-\end{array}$ & $\nabla$ \\
\hline 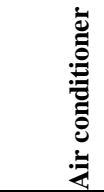 & & $\begin{array}{l}0 \\
\text { in } \\
\text { in }\end{array}$ & $\frac{\text { ô }}{i n}$ & $m$ & & $\begin{array}{l}\text { જે } \\
\text { હิ }\end{array}$ & $\begin{array}{l}\infty \\
\stackrel{\infty}{0} \\
\text { in }\end{array}$ & $m$ & & \begin{tabular}{l} 
o \\
\multirow{1}{*}{} \\
ડ่
\end{tabular} & $\begin{array}{l}\stackrel{\infty}{\sim} \\
\infty \\
\infty\end{array}$ & $\nabla$ & & $\begin{array}{l}0 \\
\infty \\
\infty \\
\infty \\
\end{array}$ & $\begin{array}{l}= \\
\stackrel{0}{\circ} \\
\curvearrowleft\end{array}$ & $\nabla$ \\
\hline 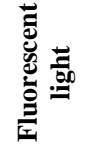 & & $\underset{i}{\vec{g}}$ & $\stackrel{\infty}{\stackrel{\infty}{\sim}} \underset{\sim}{\sim}$ & $n$ & & $\begin{array}{l}\stackrel{2}{2} \\
\stackrel{2}{2}\end{array}$ & $\frac{\stackrel{n}{n}}{n}$ & $\nabla$ & & $\begin{array}{l}\overline{6} \\
i \\
n\end{array}$ & $\stackrel{\stackrel{N}{s}}{\stackrel{i}{i}}$ & 0 & & $\begin{array}{l}n \\
\infty \\
0 \\
\end{array}$ & $\begin{array}{l}\stackrel{ \pm}{\Xi} \\
\Xi\end{array}$ & $\nabla$ \\
\hline 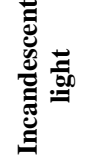 & & $\begin{array}{l}\text { oे } \\
\text { in }\end{array}$ & $\begin{array}{l}\hat{6} \\
\text { nn. }\end{array}$ & $m$ & & $\begin{array}{l}\bar{\sigma} \\
\dot{\Xi} \\
\text { ర્ల }\end{array}$ & $\begin{array}{l}\delta \\
0 \\
8\end{array}$ & $m$ & & $\begin{array}{l}8 \\
\dot{0} \\
\dot{0} \\
\stackrel{0}{0}\end{array}$ & $\begin{array}{l}\overline{6} \\
\dot{8}\end{array}$ & $\nabla$ & & $\begin{array}{l}\curvearrowleft \\
\tilde{N} \\
\infty \\
\text { d }\end{array}$ & $\begin{array}{c}0 \\
\infty \\
\infty \\
\stackrel{0}{\Xi}\end{array}$ & $m$ \\
\hline 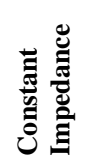 & & $\frac{n}{\stackrel{n}{r}}$ & 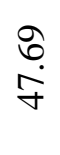 & $m$ & & $\begin{array}{l}8 \\
0 \\
\infty \\
\infty\end{array}$ & $\begin{array}{l}\infty \\
\text { Dे } \\
\dot{1}\end{array}$ & $r$ & & \begin{tabular}{l}
0 \\
\multirow{0}{0}{}
\end{tabular} & $\begin{array}{l}\text { J } \\
\text { గ্} \\
\text { N }\end{array}$ & $r$ & & $\begin{array}{l}\stackrel{\infty}{N} \\
\stackrel{N}{N} \\
\stackrel{\sim}{N}\end{array}$ & $\begin{array}{l}\infty \\
\stackrel{\infty}{2} \\
\stackrel{m}{\sim}\end{array}$ & $m$ \\
\hline
\end{tabular}




\begin{tabular}{|c|c|c|c|c|c|c|c|c|c|c|c|c|}
\hline 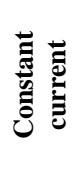 & $\begin{array}{l}\underset{\nabla}{*} \\
\stackrel{8}{n}\end{array}$ & $\begin{array}{l}\text { on } \\
\text { in }\end{array}$ & - & 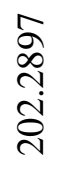 & 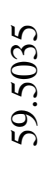 & $n$ & 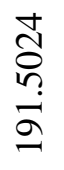 & $\begin{array}{l}n \\
\hat{\infty} \\
\infty \\
\infty\end{array}$ & 0 & $\begin{array}{l}0 \\
\infty \\
n \\
n \\
n \\
n \\
\sim\end{array}$ & $\begin{array}{l}\text { ñ } \\
\text { ?̊ } \\
\text { ñ }\end{array}$ & $N$ \\
\hline 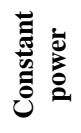 & $\frac{2}{6}$ & ते & $m$ & 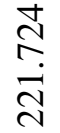 & 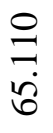 & $m$ & 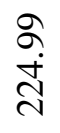 & $\begin{array}{c}\text { ণิ } \\
\text { ๙ิ }\end{array}$ & $\nabla$ & $\begin{array}{l}\stackrel{P}{n} \\
\frac{n}{n}\end{array}$ & $\begin{array}{l}\tilde{n} \\
\stackrel{\infty}{\infty} \\
\stackrel{2}{0}\end{array}$ & + \\
\hline 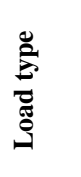 & $\frac{3}{1}$ & 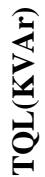 & 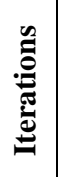 & 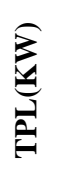 & 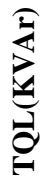 & 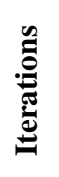 & $\frac{\widehat{a}}{1}$ & 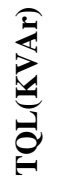 & 㺃 & $\frac{\sqrt{2}}{2}$ & 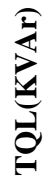 & 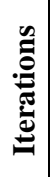 \\
\hline
\end{tabular}

7.1.4. Case 4: Industrial load of (30\% incandescent light $+49 \%$ fluorescent light + $21 \%$ air conditioner load) is considered to perform load flow analysis for different test systems. Load flow results of different test systems for the industrial load are shown in Table 7.

Table 7. Load Flow Results of Different Test Systems for the Industrial Load

\begin{tabular}{|c|c|c|c|c|}
\hline S No & System & TPL(kW) & TQL(kVAr) & Iterations \\
\hline 1 & 15 bus & 50.17 & 46.52 & 4 \\
\hline 2 & 34 bus & 189.69 & 55.0935 & 4 \\
\hline 3 & 69 bus & 170.23 & 78.04 & 5 \\
\hline 4 & 85 bus & 206.23 & 129.95 & 6 \\
\hline
\end{tabular}

7.1.5 Case 5: Commercial load of (13\% incandescent light $+39 \%$ fluorescent light $+40 \%$ air conditioner $+8 \%$ pumps \& fans load) is considered to perform load flow analysis for different test systems. Load flow results of different test systems for the commercial load are shown in Table 8.

Table 8. Load Flow Results of Different Test Systems for the Commercial Load

\begin{tabular}{|c|c|c|c|c|}
\hline S No & System & TPL(kW) & TQL(kVAr) & Iterations \\
\hline 1 & 15 bus & 51.12 & 47.39 & 4 \\
\hline 2 & 34 bus & 190.57 & 56.11 & 4 \\
\hline 3 & 69 bus & 175.49 & 81.09 & 5 \\
\hline 4 & 85 bus & 211.7 & 133.39 & 6 \\
\hline
\end{tabular}

7.1.6. Case 6: Residential load of ( $8 \%$ incandescent light $+31 \%$ air conditioner load $+23 \%$ dryer load $+13 \%$ freezer load $+25 \%$ heater load) is considered to perform load flow analysis for different test systems. Load flow results of different test systems for the residential load are shown in Table 9. 
Table 9. Load Flow Results of Different Test Systems for the Residential Load

\begin{tabular}{|l|l|l|l|l|}
\hline S.No & System & TPL(KW) & TQL(KVAR) & Iterations \\
\hline 1 & 15 bus & 53.97 & 49.50 & 3 \\
\hline 2 & 34 bus & 193.63 & 57.00 & 3 \\
\hline 3 & 69 bus & 180.92 & 82.25 & 4 \\
\hline 4 & 85 bus & 228.77 & 144.08 & 5 \\
\hline
\end{tabular}

\subsection{Load Growth Results}

The Branch path distribution load flow (BPDLF) method is used to perform the load flow analysis for different test systems to find the total real and reactive power losses, percentage increase of total real and reactive power losses and rate of increase of total real and reactive power losses for a period of 5 years, considering the four load growth rates. Load flow results of 15-bus, 34-bus, 69-bus and 85-bus systems are shown in Tables 10,11, 12 and 13 respectively.

Table 10. Load Flow Results of 15-Bus System Considering the Load Growth

\begin{tabular}{|c|c|c|c|c|c|}
\hline After 5 years & $\begin{array}{c}\text { Base } \\
\text { case }\end{array}$ & $\begin{array}{c}\mathbf{0 \%} \\
\text { Load } \\
\text { growth }\end{array}$ & $\begin{array}{c}\mathbf{2 \%} \\
\text { Load } \\
\text { growth }\end{array}$ & $\begin{array}{c}\mathbf{5 \%} \\
\text { Load } \\
\text { growth }\end{array}$ & $\begin{array}{c}\mathbf{7 \%} \\
\text { Load } \\
\text { growth }\end{array}$ \\
\hline TPL(KW) & 61.79 & 61.79 & 76.14 & 103.64 & 126.91 \\
\hline TQL(KVAR) & 57.29 & 57.29 & 70.60 & 96.10 & 117.6846 \\
\hline \% Increase of TPL & - & 0.0000 & 23.23 & 67.72 & 105.37 \\
\hline \% Increase of TQL & - & 0.0000 & 23.23 & 67.73 & 105.39 \\
\hline Rate of increase of TPL & - & 0.0000 & 4.26 & 10.89 & 15.48 \\
\hline Rate of increase of TQL & - & 0.0000 & 4.2666 & 10.89 & 15.48 \\
\hline
\end{tabular}

Table 11. Load Flow Results of 34-bus System Considering the Load Growth

\begin{tabular}{|c|c|c|c|c|c|}
\hline After 5 years & $\begin{array}{c}\text { Base } \\
\text { case }\end{array}$ & $\begin{array}{c}\mathbf{0 \%} \\
\text { Load } \\
\text { growth }\end{array}$ & $\begin{array}{c}\mathbf{2 \%} \\
\text { Load } \\
\text { growth }\end{array}$ & $\begin{array}{c}\mathbf{5 \%} \\
\text { Load } \\
\text { growth }\end{array}$ & $\begin{array}{c}\mathbf{7 \%} \\
\text { Load } \\
\text { growth }\end{array}$ \\
\hline TPL(KW) & 221.72 & 221.72 & 273.1 & 371.42 & 454.54 \\
\hline TQL(KVAr) & 65.11 & 65.11 & 80.18 & 109.01 & 133.37 \\
\hline \% Increase of TPL & - & 0.0000 & 23.17 & 67.51 & 105.00 \\
\hline \% Increase of TQL & - & 0.0000 & 23.15 & 67.43 & 104.84 \\
\hline Rate of increase of TPL & - & 0.0000 & 4.25 & 10.86 & 15.43 \\
\hline Rate of increase of TQL & - & 0.0000 & 4.25 & 10.85 & 15.42 \\
\hline
\end{tabular}


Table 12. Load Flow Results of 69-Bus System Considering the Load Growth

\begin{tabular}{|c|c|l|l|l|l|}
\hline After 5 years & $\begin{array}{c}\text { Base } \\
\text { case }\end{array}$ & $\begin{array}{c}\text { 0\% Load } \\
\text { growth }\end{array}$ & $\begin{array}{c}\text { 2\% } \\
\text { Load } \\
\text { growth }\end{array}$ & $\begin{array}{c}\text { 5\% Load } \\
\text { growth }\end{array}$ & $\begin{array}{c}\text { 7\% Load } \\
\text { growth }\end{array}$ \\
\hline TPL(KW) & 225.00 & 225.00 & 279.73 & 386.81 & 479.70 \\
\hline TQL(KVAr) & 102.20 & 102.20 & 126.92 & 175.17 & 216.91 \\
\hline \% Increase of TPL & - & 0.0000 & 24.32 & 71.91 & 113.19 \\
\hline \% Increase of TQL & - & 0.0000 & 24.18 & 71.39 & 112.23 \\
\hline Rate of increase of TPL & - & 0.0000 & 4.45 & 11.44 & 16.34 \\
\hline Rate of increase of TQL & - & 0.0000 & 4.427 & 11.37 & 16.24 \\
\hline
\end{tabular}

Table 13. Load Flow Results of 85-Bus System Considering the Load Growth

\begin{tabular}{|c|c|c|c|c|c|}
\hline After 5 years & $\begin{array}{c}\text { Base } \\
\text { case }\end{array}$ & $\begin{array}{c}\text { 0\% Load } \\
\text { growth }\end{array}$ & $\begin{array}{c}\mathbf{2 \%} \\
\text { Load } \\
\text { growth }\end{array}$ & $\begin{array}{c}\text { 5\% Load } \\
\text { growth }\end{array}$ & $\begin{array}{c}\text { 7\% Load } \\
\text { growth }\end{array}$ \\
\hline TPL(KW) & 315.70 & 315.70 & 395.90 & 556.31 & 699.25 \\
\hline TQL(KVAr & 198.35 & 198.35 & 248.69 & 349.29 & 438088 \\
\hline \% Increase of TPL & - & 0.0000 & 25.40 & 76.21 & 121.49 \\
\hline \% Increase of TQL & - & 0.0000 & 25.37 & 76.09 & 121.25 \\
\hline Rate of increase of TPL & - & 0.0000 & 4.631 & 11.99 & 17.239 \\
\hline Rate of increase of TQL & - & 0.0000 & 4.62 & 11.98 & 17.21 \\
\hline
\end{tabular}

\section{Conclusions}

In this paper a simple and efficient load flow algorithm is proposed by using Branch path matrix. The proposed load flow method has been tested on various IEEE test systems. The proposed algorithm has better convergence characteristics, and is reasonably accurate in obtaining the load flow solution of radial distribution systems, and also it requires less memory. The proposed algorithm uses only branch path matrix for calculations which saves the computational time. The load flow results shows that the radial distribution systems with different types of static or composite loads can be efficiently solved by using the proposed method. The future losses of distribution systems by considering the effect of load growth on various distribution systems can also be analysed efficiently by using proposed method. The proposed method is therefore capable of performing power flow analysis of radial distribution systems with any number of buses or any types of static loads. The proposed method is accurate and efficient for studies on distribution system planning problems.

\section{References}

[1] W. G. Tinney and C. E. Hart, "Power flow solutions by Newton's method", IEEE Trans. Power Apparatus Syst., vol. 86, (1967), pp. 1449-1457.

[2] R. Berg, E.S. Hawkins and W.W. Plelines, "Mechanized Calculation of Unbalanced Load Flow on Radial Distribution Circuits", IEEE Trans. on Power Apparatus and Systems, vol. 86, no. 4, (1967), pp.415-421. 
[3] B. Stott and O. Alsac, "Fast decoupled load flow", IEEE Trans. Power Apparatus Syst., vol. 93, no. 3, pp. 859-869, 1974.

[4] B. Stott, "Review of Load-Flow Calculation Methods", Proceedings of the IEEE, vol. 62, no. 7, (1974), pp.916-929.

[5] S. Iwamoto and Y. Tamura, "A load flow-calculation method for ill-conditioned power systems", IEEE Trans. Power Apparatus Syst., vol. 100, no. 4, (1981), pp. 1736-1743.

[6] S. C. Tripathy, G. D. Prasad, O. P. Malik and G. S. Hope, "Load flow solutions for ill-conditioned power systems by a Newton-like method”, IEEE Trans. Power Apparatus Syst., vol. 101,n. 10, (1982), pp. 3648-3657.

[7] G. X. Luo and A. Semlyen, "Efficient load flow for large weakly meshed networks", IEEE Trans. Power Syst., vol. 5, no. 4, (1990), pp. 1309-1316.

[8] F.D. Gallana and Z.C. Zeng, "Analysis of the load flow behaviour near a Jacobian singularity", IEEE Transactions on Power Systems, vol. 7, (1992), pp. 1362-1369.

[9] D. Das, D. P. Kothari and A. Kalam, "Simple and efficient method for load flow solution of radial distribution networks", Elec. Power Energy Syst., vol. 17, no. 5, (1995), pp. 335-346.

[10] . M. H. Haque, "Load flow-solution of distribution systems with voltage dependent load models", Elec. Power Syst. Res., vol. 36, (1996), pp. 151-156.

[11] M.H. Haque, "Efficient load flow method for distribution systems with radial or mesh configuration", IEE Proc.,Gener. transm.Distrib.,1996, vol. 143, no. 1,pp33-38

[12] Xiao-Ping Zhang: 'Fast Three Phase Load Flow Methods', IEEE Trans. on Power Syst,1996,11,(3),pp.1547-1554

[13] Hieu Le Nguyen: 'Newton-Raphson Method in Complex Form', IEEE Trans. Power Syst., 1997,12,(3),pp.1355-1359

[14] S. Ghosh, D. Das, "Method for load-flow solution of radial distribution networks," IEE Proc - Gener Transm Distr., vol. 146, no. 6, pp. 641-48,1999.

[15] M. H. Haque, "A general load flow method for distribution systems," Elect. Power Systems Research, vol. 54, pp. 47-54, 2000.

[16] A. Augugliaro, L. Dusonchet, M. G. Ippolito and E. Riva Sanseverino, "An efficient iterative method for load-flow solution in radial distribution networks", Proceedings of IEEE Porto power tech.,(2001), pp. $10-13$.

[17] S. F. Mekhamer, S. A. Soliman, M. A. Moustafa and M. E. El-Hawary, "Load flow solution of radial distribution feeders: a new contribution”, Elect. Power Energy Syst., vol. 24, no. 9, (2002), pp. 701-707.

[18] J.-H. Heng and C.-Y. Chang, "A novel and Fast Three-Phase Load Flow for Unbalanaced Radial Distribution Systems", IEEE Trans.Power Syst., vol. 17, no. 4, (2002), pp.1238-1244.

[19] J. H. Teng, “A Direct Approach for Distribution System Load Flow Solutions", IEEE Trans. on Power delivery, vol. 18, no. 3, (2003), pp.882-887.

[20] S. Herraiz, L. Sainz and J. Clua, "Review of Harmonic Load Flow Formulations", IEEE Trans. On Power Delivery, vol. 18, no. 3, (2003), pp. 1079-1087.

[21] B. Venkatesh and R. Ranjan, "Data structure for radial distribution system load flow analysis", IEE Proceedings Generation, Transmission and Distribution, vol. 150, (2003), pp. 101-106

[22] S. Satyanarayana, T. Raman, S. Sivanagaraju and G. K. Rao, "An efficient load flow solution for radial distribution network including voltage dependent load models", Elect Power Comp. and Syst., vol. 35, no. 5, (2007), pp. 539-551.

[23] G.W. Chang, S.Y. Chu and H.L. Wang, "An Improved Backward/Forward Sweep Load Flow Algorithm for Radial Distribution Systems”, IEEE Trans. on Power Systems, vol. 22, no. 2, (2007), pp.882-884

[24] K. V. S. R. Murthy, M. R. Raju, G. G. Rao and K. N. Rao, "Topology based approach for Efficient Load flow Solution of Radial Distribution Networks", 16th National Power Systems Conf. , (2010), pp. 17619.

[25] K. Nagaraju, S. Sivanagaraju, T. Raman and P. V. Prasad, "A novel load flow method for radial distribution system for realistic loads", Elect Power Comp. and Syst., vol. 39, no. 2, (2011), pp.128-141.

[26] A. Hamouda and K. Zehar, "Improved algorithm for radial distribution networks load flow solution", Elect. Power and Energy Syst., vol. 33, (2011), pp. 508-514.

[27] S. Singh and T.Ghose, "Improved radial load flow method", Elect. Power and Energy Syst., vol. 44, (2013), pp. 721-727.

[28] M. Farivar and S. Low, "Branch flow model: Relaxations and convexification: Part I", Power Systems, IEEE Transactions on, vol. 28, no. 3, (2013), pp. 2554-2564.

[29] R. Madani, S. Sojoudi and J. Lavaei, "Convex relaxation for optimal power flow problem: Mesh networks", Power Systems, IEEE Transactions on, vol. 30, no. 1, (2015), pp. 199-211.

[30] D. Molzahn, B. Lesieutre and C. DeMarco, "A sufficient condition for global optimality of solutions to the optimal power flow problem", Power Systems, IEEE Transactions on, vol. 29, no. 2, (2014), pp. 978-979.

[31] S. Bose, S. Low, T. Teeraratkul and B. Hassibi, "Equivalent relaxations of optimal power flow", Automatic Control, IEEE Transactions on, vol. PP, no. 99, (2014), pp. 1-1.

[32] L. Gan, N. Li, U. Topcu and S. Low, "Exact convex relaxation of optimal power flow in radial networks", Automatic Control, IEEE Transactions on, vol. 60, no. 1, (2015), pp. 72-87. 
[33] M. Andersen, A. Hansson and L. Vandenberghe, "Reduced-complexity semidefinite relaxations of optimal power flow problems", Power Systems, IEEE Transactions on, vol. 29, no. 4, (2014), pp. 18551863.

[34] W. Bukhsh, A. Grothey, K. McKinnon and P. Trodden, "Local solutions of the optimal power flow problem”, Power Systems, IEEE Transactions on, vol. 28, no. 4, (2013), pp. 4780-4788.

[35] S. Bolognani and S. Zampieri, "On the existence and linear approximation of the power flow solution in power distribution networks", Power Systems, IEEE Transactions on, vol. PP, no. 99, (2015), pp. 1-10.

[36] A. Garces, "A linear three-phase load flow for power distribution systems", Power Systems, IEEE Transactions on, vol. PP, no. 99, (2015), pp. 1-2.

[37] S. Satyanarayana, "An efficient load flow solution for radial distribution network including voltage dependent load models", Electric Power Components and Systems, vol. 35.5, (2007), pp. 539-551.

[38] K., Nagaraju, "A Novel Load Flow Method for Radial Distribution Systems for Realistic Loads", Electric Power Components and Systems, vol. 39.2, (2011), pp. 128-141.

[39] A. Wafa and R. Ahmed, "A network-topology-based load flow for radial distribution networks with composite and exponential load", Electric Power Systems Research, vol. 91, (2012), pp. 37-43. 